Michael A. Ashburn MD, James B. Streisand MD, Stephen D. Tarver MD, Scott L. Mears MD, Sandra M. Mulder MD, Annemiek Wilms Floet DRS, Roland Walter Luijendijk DRS, Richard A. Elwyn MD, Nathan L. Pace MD, Theodore H. Stanley MD

\section{Oral transmucosal fentanyl citrate for premedication in paediatric outpatients}

Two doses (10-15 $\mu \mathrm{g} \cdot \mathrm{kg}^{-1}$, Group I, and 15-20 $\mu \mathrm{g} \cdot \mathrm{kg}^{-1}$, Group (I) of oral transmucosal fentanyl citrate (OTFC) plus a placebo (Group III) were evaluated for premedication in 105 healthy children, aged 2 to $13 \mathrm{yr}$, undergoing short $(</ \mathrm{hr})$ operations in the hospilal short-stay unit. The study was randomized and double-blinded and 91 of the 105 children also received droperidol, $25 \mu \mathrm{g} \cdot \mathrm{kg}^{-1} \mathrm{IV}$, after induction of anaes. thesia with halothane and $\mathrm{N}_{2} \mathrm{O}$ in oxygen. Both doses of OTFC produced significantly greater sedation (first present at $20 \mathrm{~min}$ ) and anxiolysis (first presem in Group I at $40 \mathrm{~min}$ ) than the placebo. Recovery times were similar in the three groups and analgesic requirements in the recovery room were significantly lower in Group I than Group III. Both OTFC groups took longer to tolerate oral fluids in the postoperative discharge unit than the placebo group and this caused patients in Group / to have a delayed discharge from the hospital compared to Group III. Preoperalive pruritus accurred significanly more frequently in Groups I and II ( 58 and 76 per cent, respectively) Ihan Group III (23 per cent). Although the incidences of nausea and vomiting tended to be slightly higher in the OTFC groups in the preoperative holding and postoperative discharge units, the differences among the groups were not statistically significant. Likewise droperidol did not reduce the incidence of postoperative nausea or vomiting. The data indicate that OTFC may be a safe and effective premedicant in paediatric patients having short operations but delays discharge from the hospital by 30-50 min) by delaying the time patients tolerate fluids early after operation.

\section{Key words}

ANAESTHESIA: outpatient, paediatric;

ANALGESICS: fentanyl;

PREMEDICATION: oral transmucosal fentanyl.

From the Departments of Anesthesiology, the Primary Children's Hospital and the University of Utah School of Medicine, Salt Lake City, Utah.

Address correspondence to: Dr. M. A. Ashburn, Department of Anesthesiology, University of Utah School of Medicine, 50 North Medical Drive, Salt Lake City, Utah 84132.

Supported in part by Stanley Research Foundation and Anesta Corp., Salt Lake City, Utah.
Deux doses $\left(10-15 \mu \mathrm{g} \cdot \mathrm{kg}^{-1}\right.$, le groupe I et $15-20 \mu \mathrm{g} \cdot \mathrm{kg}^{-1}$, le groupe (I) de citrate de fentanyl par voie transmuqueuse (OTFC) plus un placebo (groupe III) ont éré évalué comme prémédication chez 105 enfants en bonne samté âgés de 2 à 13 ans devant subir une chirurgie de courle durée $(<1$ hre). L'étude fut randomisé et à double insu, 91 des 105 enfants ont reçu du droperidol, $25 \mu \mathrm{g} \cdot \mathrm{kg}^{-1}$, par voie intraveineuse après l'induction de l'anesthésie avec l'halothane et le protoryde d'azote-oxygène. Les deux doses d'OTFC ont produit une sédation significativement plus grande (initialement présente à 20 minutes) et une anxiolyse (initiatement présente dans le groupe (à 40 minutes) que le placebo. Les temps de récupéra. tion furent similaires dans les trois groupes et les demandes en analgésiques en salle de réveil furent significativement plus basses dans le groupe I que dans le groupe III. Les deux groupes OTFC ont pris plus de temps pour tolérer l'ingestion de liquide en salle de réveil que le groupe placébo et ceci a retardé le congé des patients du groupe I comparativement au groupe III. Un prurit pré-opératoire est survenu significative. ment plus fréquemment dans les groupes I et II (58 et 76 pour cent respectivement) que le groupe III (23 pour cent). Mêmes si les incidences de nausées et de vomissements ont ell une lendance à être supérieures dans les groupes OTFC, les différences entre les groupes n'étaient pas statistiquement significatives. De même, le droperidol n' a pas réduit l' incidence de nausées ou de vomissements post-opératoires. Les données indiquent que l'OTFC peut être une prémédication sécuritaire et efficace chez les patients pédiatriques devant subir de courtes opérations mais qu'elle peut retarder le congé de l'hôpilal (entre 30 et 50 minutes) en retardant le temps pour la tolérance de l'ingestion de liquide après l'opération.

Oral transmucosal fentanyl citrate produces dosedependent increases in sedation and analgesia in adult volunteers' and has proven safe and effective as a premedicant in studies involving mixtures of paediatric inpatients and outpatients. ${ }^{2-5}$ At the present time most paediatric surgery in North America is performed in outpatients requiring rapid turnover. The purpose of this study was to evaluate two doses of oral transmucosal fentanyl citrate (OTFC) as a premedication in children 
TABLE I Scoring schedules for preoperative activity (sedation), anxiety, cooperation, anaesthetic induction, and emergence

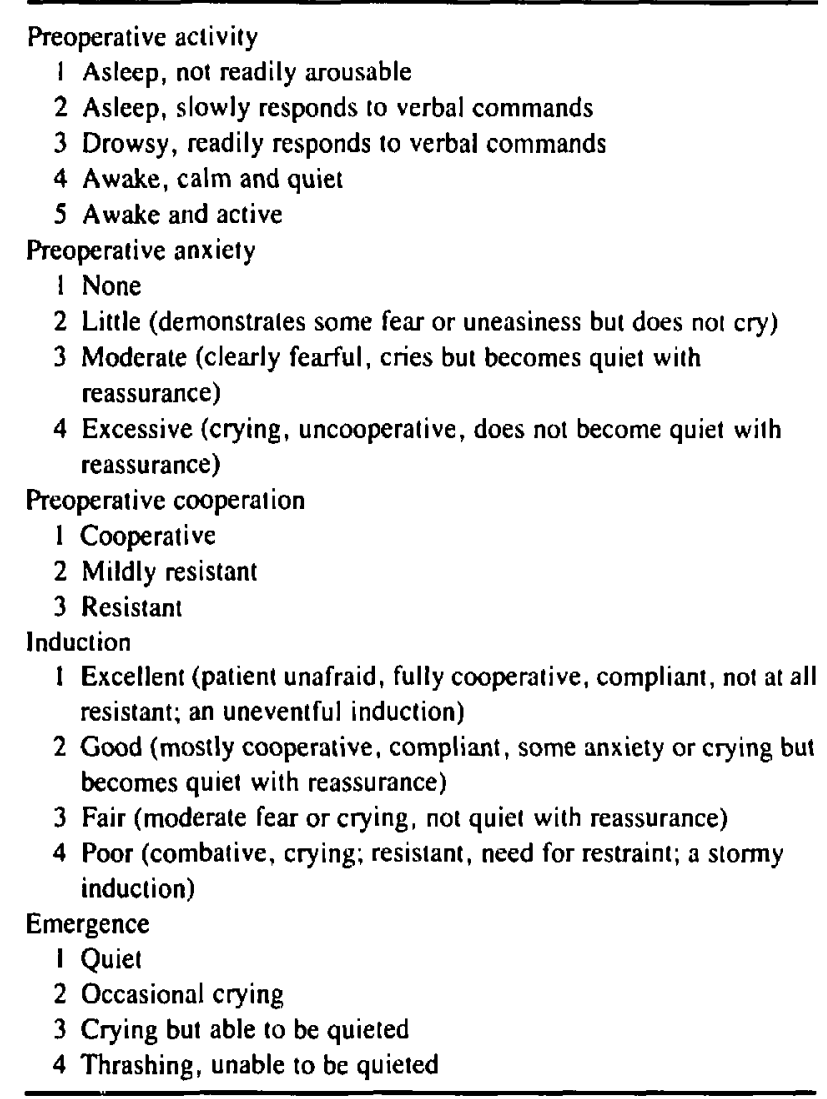

coming for day surgery in the short-stay unit of a major paediatric hospital.

\section{Methods}

Approval was received from the U.S. Food and Drug Administration and the Human Institutional Review Board of the Primary Children's Medical Center of Salt Lake City. Consent was obtained from the parents of 117 ASA physical status I-II children, 2 to $13 \mathrm{yr}$ of age scheduled as outpatients for a variety of short (approximately one hour or less) elective ophthalmological, otolaryngological (ENT), urological, orthopaedic and general surgical operations. After consent was obtained, the children were randomly assigned to one of three groups: Group I received a low dose OTFC unit containing $10-15 \mu \mathrm{g} \cdot \mathrm{kg}^{-1}$ of fentanyl citrate; Group II received a higher dose OTFC unit containing $15-20 \mu \mathrm{g} \cdot \mathrm{kg}^{-1}$ of fentanyl citrate; and Group III received a placebo OTFC unit containing no fentanyl. The OTFC units were made by heating a sweetened base and adding 100, 200, 250, 300, $400,500,700$ or $1000 \mu \mathrm{g}$ of fentanyl citrate crystals. Following mixing, the fentanyl mixture was poured into moulds, a handle was added, and the unit was allowed to cool and harden before removal from the moulds. The placebos were made in the same fashion with the exception that fentanyl citrate was not added to the mixture. All OTFC and placebos were the same size (1.6 $\mathrm{ml}$ ) and the study was both randomized and doubleblinded.

Premedication using placebo or active OTFC units was given to each child (accompanied by his or her parents) approximately 30 to $60 \mathrm{~min}$ before the scheduled beginning of the operation in the preoperative holding area adjacent to the operating room. Following examination of the patient's oral mucosa, baseline systolic and diastolic arterial blood pressures, heart rate, respiratory rate and oxygen saturation $\left(\mathrm{SpO}_{2}\right)$ were measured by a Criticon (Dinamap ${ }^{(\pi)}$ ) paediatric blood pressure monitor (model 8100 ), radial artery palpation, observation of the chest wall, and use of a Nellcor model 200 pulse oximeter, respectively. The patients then received either the placebo, low or higher dose OTFC units and were asked to suck them rapidly without biting or chewing; the time for their complete consumption was recorded.

The $\mathrm{SpO}_{2}$ was continuously measured, and heart rate, systolic and diastolic arterial blood pressures, and respiratory rate were remeasured every ten minutes throughout the preanaesthetic evaluation period until the children were taken to the operating room. Activity, anxiety, and cooperation scores, evaluating the effectiveness of the premedication (Table I), were determined prior to administration of the premedication and every ten minutes thereafter until the children were taken to the operating room. Prior to departure to the operating room, the patient's oral mucosa was reexamined.

Anaesthesia was induced with halothane $(0.25-4.0$ per cent) and $\mathrm{N}_{2} \mathrm{O}$ (60 per cent) in oxygen via a face mask. Ventilation was at first spontaneous, then assisted, and finally controlled as the patient lost consciousness. Speed of induction, as determined every 15 to $20 \mathrm{sec}$ and measured from the start of induction to the loss of consciousness, was recorded. The presence of airway obstruction (none, corrected by repositioning, corrected with an artificial airway), secretions (none, mild, moderate, excessive) and laryngospasm (none, mild, moderate, severe) were also recorded. Following loss of consciousness an IV infusion of 5 per cent dextrose and 0.25 per cent normal saline or lactated Ringer's solution was started in a hand or arm vein. The trachea was then intubated without the use of a muscle relaxant. The ease and quality of anaesthetic induction was evaluated according to an anaesthetic induction score (Table I). Anaesthesia was maintained with halothane (0.1-2.5 per cent) or, if arrhythmias occurred (in two patients), with isoflurane (0.2-2.0 per cent) and $\mathrm{N}_{2} \mathrm{O}$ (60 per cent) in oxygen; inspired concentrations were adjusted to keep systolic arterial blood pressure within 20 per cent of preoperative values. No opiates or IV supplements were to be used, but after the first 14 patients were entered into 
TABLE I] Demographic data in 105 children receiving premedication with oral transmucosal fentanyl citrate (OTFC) or a placebo (mean $\pm \mathrm{SD})$

\begin{tabular}{lccc}
\hline & $\begin{array}{l}\text { Group I } \\
\text { OTFC } \\
\text { IO-15 } \mu \mathrm{g} \cdot \mathrm{kg}^{-1}\end{array}$ & $\begin{array}{l}\text { Group II } \\
\text { OTFC } \\
15-20 \mu \mathrm{g} \cdot \mathrm{kg}^{-1}\end{array}$ & $\begin{array}{l}\text { Group III } \\
\text { Placebo }\end{array}$ \\
\hline Sex (M/F) & $23 / 13$ & $20 / 14$ & $20 / 15$ \\
Age (yr) & $5.8 \pm 3.1$ & $4.6 \pm 2.3$ & $5.5 \pm 2.9$ \\
Weight (kg) & $21.1 \pm 8.6$ & $18.3 \pm 4.8$ & $19.6 \pm 7.0$ \\
Height (cm) & $44.0 \pm 7.4$ & $42.0 \pm 5.3$ & $43.7 \pm 6.6$ \\
Duration of anaesthesia (min) & $43.7 \pm 36.4$ & $50.0 \pm 41.7$ & $41.7 \pm 31.4$ \\
\hline
\end{tabular}

the study droperidol $\left(25 \mu \mathrm{g} \cdot \mathrm{kg}^{-1}\right)$ was given intravenously after anaesthetic induction in an effort to reduce postoperative nausea and vomiting. Muscle relaxants were used after tracheal intubation if clinically indicated. In most patients the lungs were ventilated mechanically until 10 to $20 \mathrm{~min}$ before the end of the operation when halothane was decreased or discontinued and spontaneous ventilation resumed. After termination of all anaesthetics, patients' tracheas were extubated when they responded to the tracheal tube, the respiratory rate was $>12$ breaths $\cdot \mathrm{min}^{-1}$, and tidal volume was considered to be adequate.

Emergence from anaesthesia was evaluated in the operating room, upon arrival in the recovery room and every 15 min thereafter using an emergence score (Table I). Times to awakening (as measured from termination of all inhalation anaesthetics until eye opening first occurred spontaneously and upon command) were evaluated every five minutes in the recovery room and recorded. Analgesics (acetaminophen, acetaminophen with codeine, and fentanyl) were requested by the recovery room nurses (who were unaware of the premedication used) for control of moderate or severe postoperative pain (as determined by an anaesthetist uninvolved with the study). No specific criteria defined moderate or severe pain nor drugs and doses used for analgesia. Patients were discharged from the recovery room to the outpatient discharge unit when they achieved a score of 10 using the Aldrete postanaesthetic recovery score. ${ }^{6}$ Patients were discharged from the hospital when their vital signs were stable for one hour, they were oriented to person, place and time and they could tolerate oral fluids and ambulate without difficulty. Time of fulfillment of discharge criteria was recorded. The incidences and times of occurrence of pruritus and nausea (as volunteered by the patient) and vomiting were recorded in the preoperative holding area, the operating and recovery rooms and the post-recovery room outpatient discharge unit.

Data were analyzed for statistical significance using a one-way analysis of variance (ANOVA) for age, weight, height, duration of anaesthesia, vital signs, and $\mathrm{SpO}_{2}$. Individual comparisons for age, weight and height were performed by the multiple-range test. Bartlett's test was used to assess homogeneily of variance among study groups and Tukey's HSD multiple comparisons were used for pair-wise comparisons of vital signs and $\mathrm{SpO}_{2}$. Changes with time for vital signs were evaluated by a repeated measures ANOVA with polynomial contrasts for linear trends. Sex and type of operation were compared using chi-square tests. Activity ratings were analyzed at each evaluation period and were grouped as asleep/ drowsy (activity scores 1-3) versus awake (scores 4 and 5) due to small numbers in most categories and then compared using chi-square tests. Anxiety ratings were grouped as per cent of patients with no apprehension (anxiety score 1) and compared with those with little, moderate or severe anxiety (scores 2 to 4) using chisquare tests. Changes in anxiety and activity scores from baseline were analyzed using chi-square tests and chisquare multiple comparisons. Recovery room and postrecovery data and side effects were analyzed using chisquare tests, the Kruskal-Wallis test and Dunn's multiple comparisons. The majority of analyses were performed using the SYSTAT statistical package of the IBM-PC. $P<0.05$ was considered statistically significant.

\section{Results}

Data from 12 of 117 patients entered into the study were not evaluated because less than 30 or more than 120 minutes had elapsed between administration of the OTFC or placebos and induction of anaesthesia $(n=5)$, the patient bit or swallowed the study unit $(n=1)$ or the patient never received, refused or failed to complete the study unit $(n=6)$. Of the 105 children suitable for evaluation 36 received OTFC, $10-15 \mu \mathrm{g} \cdot \mathrm{kg}^{-1}$ (Group I), 34 received OTFC, $15-20 \mu \mathrm{g} \cdot \mathrm{kg}^{-1}$ (Group II), and 35 received a placebo (Group III). The three groups were similar with respect to age, weight, height, sex distribution (Table II), distribution of surgical procedures performed,* ASA physical status distribution, baseline vital signs (with the exception of diastolic blood pressure of the placebo group which was significantly higher than Group I) and oxygen saturation, and duration of anaesthesia.

*Sixty per cent of all patients (53-69 per cent in the three groups) had a tonsillectomy with or without adenoidectomy. 


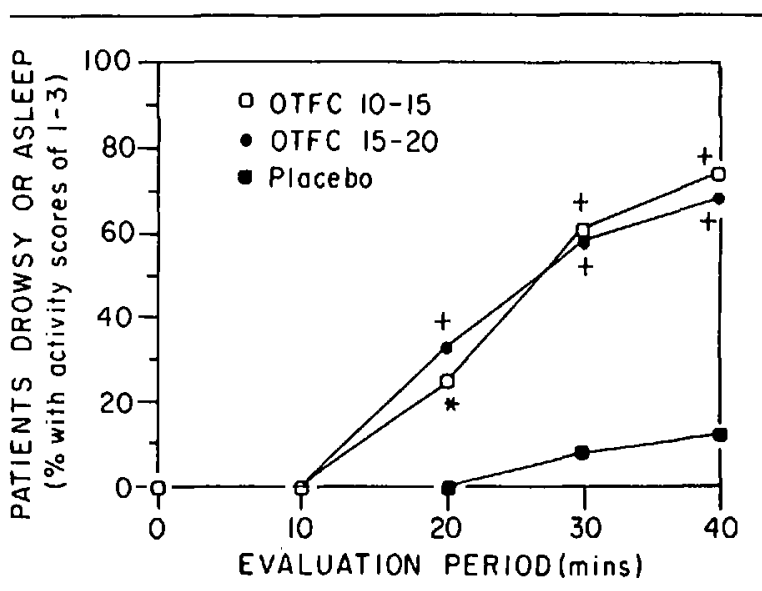

FIGURE 1 Per cent of patients drowsy or asleep (activity scores of 1-3) as a function of time. Except at 40 min there were 36 patients receiving OTFC, $10-15 \mu \mathrm{g} \cdot \mathrm{kg}^{-1}, 34$ receiving OTFC, 15-20 $\mu \mathrm{g} \cdot \mathrm{kg}^{-1}$, and 35 receiving a placebo. ${ }^{*} P<0.01, \dagger P<0.001$, compared with placebo, chi-square test.

Groups I to III required $12.9 \pm 5.3,13.8 \pm 8.9$ and 11.9 $\pm 5.7 \mathrm{~min}$ (range $2-50 \mathrm{~min}$ ), respectively, to consume their OTFC or placebo units. The differences in consumption times between the groups were not statistically significant. All oral mucosal observations before and after consumption of OTFC and placebo units were recorded as normal.

The 105 children completing the study had preoperative evaluations for at least $30 \mathrm{~min}$ after baseline and until they were brought to the operating room. The number of children evaluated in the three groups decreased with each additional 10 - $\mathrm{min}$ interval after $30 \mathrm{~min}$ as increasing numbers of patients were called to the operating room. Evaluations at $40 \mathrm{~min}$ after baseline included 76 patients (27, 25 and 24 in Goups I-III, respectively), whereas 50 and $60 \mathrm{~min}$ after baseline $53(15,22$ and 16 in Groups I-III, respectively) and 37 (II, 14 and 12 in Groups I-III, respectively) patients were evaluated.

Figure I describes the per cent of patients drowsy or asleep (activity scores of $1-3$ ) as a function of time. Figure 2 describes the per cent of patients apprehensive (anxiety scores 2-4) as a function of time. Tables III and IV provide complete activity and anxiety scoring results for $60 \mathrm{~min}$. Evaluations past $40 \mathrm{~min}$ after baseline are not included in the figures because the number of patients within each group decreased dramatically at these periods. No patient in any group was sleepy or drowsy (activity scores 1, 2 or 3) at baseline or after $10 \mathrm{~min}$ of placebo or OTFC consumption; however, from 20 to 60 min both OTFC groups had significantly more patients asleep and drowsy than the placebo group (Figure 1). Analysis of change in activity from baseline showed that the two OTFC groups had comparable increases in

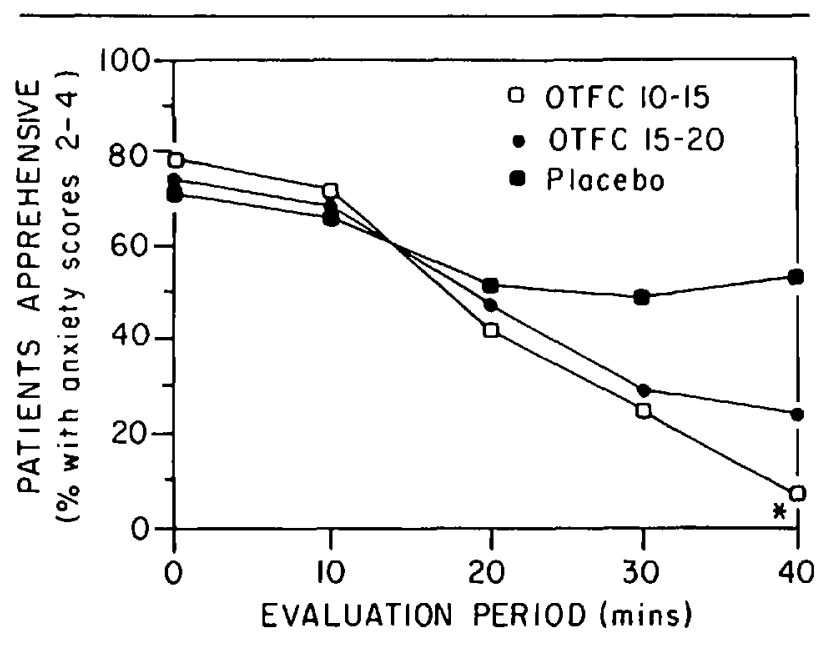

FIGURE 2 Per cent of patients apprehensive (anxiety scores of 2-4) as a function of time. Except at $40 \mathrm{~min}$ there were 36 patients receiving OTFC, $10-15 \mu \mathrm{g} \cdot \mathrm{kg}^{-1}, 34$ receiving OTFC, 15-20 $\mu \mathrm{g} \cdot \mathrm{kg}^{-1}$, and 35 receiving a placebo. Changes with time for vital signs were evaluated by a repeated measures ANOVA with polynomial contrasts for linear trends. ${ }^{*} P<0.001$ compared to placebo, chi-square test.

sedation with time. The time of greatest sedation (lowest activity score) was significantly longer for both OTFC groups (median $=30 \mathrm{~min}$ ) than the placebo group (median $=10 \mathrm{~min}$ ). At these times both OTFC groups had significantly more patients that were drowsy or asleep than the placebo group; differences between the two OTFC groups were not significant.

All three groups had comparable degrees of anxiety from baseline through $30 \mathrm{~min}$; however, the 10-15 $\mu \mathrm{g} \cdot \mathrm{kg}^{-1}$ OTFC group had significantly less apprehension than the placebo group by $40 \mathrm{~min}$ (Figure 2), and both OTFC groups had less apprehension than the placebo group at $50 \mathrm{~min}$. Analysis of change in apprehension scores from baseline through $60 \mathrm{~min}$ showed no statistically significant differences between the groups. The time of least apprehension was a median of $10 \mathrm{~min}$ after the placebo and $20 \mathrm{~min}$ after both OTFC units. These differences were not statistically significant.

The three groups were comparable in the proportion of patients that were cooperative versus resistant throughout the study. Likewise separation, preinduction and induction scores and induction times were similar amongst the three groups. Induction times (from beginning the inhalational agents until loss of consciousness) averaged $2.9 \pm$ $1.1,2.6 \pm 1.1$, and $2.9 \pm 1.0 \mathrm{~min}$ in Groups I to III, respectively, and ranged from 1 to $6 \mathrm{~min}$.

Heart rates of the three groups were statistically comparable throughout the preoperative holding area evaluations. There were no clinically significant blood pressure changes in the preoperative period. However, repeated measures ANOVA and tests for linear trends 
TABLE III Activity data in 105 children given oral transmucosal fentanyl citrate (OTFC) or a placebo for premedication

\begin{tabular}{|c|c|c|c|c|c|c|c|}
\hline \multirow[b]{3}{*}{ Time, score } & \multicolumn{7}{|c|}{ Number of patients and per cent of group } \\
\hline & \multicolumn{2}{|c|}{$10-15 \mu g \cdot \mathrm{kg}^{-1}$} & \multicolumn{2}{|c|}{$15-20 \mu g \cdot k^{-1}$} & \multicolumn{2}{|c|}{ Placebo } & \multirow{2}{*}{$\frac{\text { Total }}{n}$} \\
\hline & $n$ & percent & $n$ & percent & $n$ & percent & \\
\hline \multicolumn{8}{|l|}{ Baseline } \\
\hline Awake/calm & 9 & 25 & 12 & 35 & 13 & 37 & 34 \\
\hline Awake/active & 27 & 75 & 22 & 65 & 22 & 63 & 71 \\
\hline \multicolumn{8}{|l|}{10 minutes } \\
\hline Awake/calm & 20 & 56 & 17 & 50 & 18 & 51 & 55 \\
\hline Awake/active & 16 & 44 & 17 & 50 & 17 & 49 & 50 \\
\hline \multicolumn{8}{|l|}{20 minutes } \\
\hline Asleep/slow & 0 & 0 & 2 & 6 & 0 & 0 & 2 \\
\hline Drowsy & 9 & 25 & 9 & 26 & 0 & 0 & 18 \\
\hline Awake/calm & 14 & 39 & 12 & 35 & 25 & 71 & 51 \\
\hline Awake/aclive & 13 & 36 & 11 & 32 & 10 & 29 & 34 \\
\hline \multicolumn{8}{|l|}{30 minutes } \\
\hline Asleep/no response & I & 3 & I & 3 & 0 & 0 & 2 \\
\hline Asleep/responds & 6 & 17 & 8 & 24 & 0 & 0 & 14 \\
\hline Drowsy & 15 & 42 & 11 & 32 & 3 & 9 & 29 \\
\hline Awake/calm & 8 & 22 & 6 & 18 & 23 & 66 & 37 \\
\hline Awake/aclive & 6 & 17 & 8 & 24 & 9 & 26 & 23 \\
\hline \multicolumn{8}{|l|}{40 minutes } \\
\hline Asleep/no response & 2 & 7 & 0 & 0 & 0 & 0 & 2 \\
\hline Asleep/responds & 6 & 22 & 7 & 28 & 0 & 0 & 13 \\
\hline Drowsy & 12 & 44 & 10 & 40 & 3 & 13 & 25 \\
\hline Awake/calm & 4 & 15 & 3 & 12 & 14 & 58 & 21 \\
\hline Awake/active & 3 & 11 & 5 & 20 & 7 & 29 & 15 \\
\hline \multicolumn{8}{|l|}{50 minutes } \\
\hline Asleep/no response & 1 & 7 & 3 & 14 & 0 & 0 & 4 \\
\hline Asleep/responds & 5 & 33 & 5 & 23 & 0 & 0 & 10 \\
\hline Drowsy & 7 & 47 & 11 & 50 & 4 & 25 & 22 \\
\hline Awake/calm & 1 & 7 & 2 & 9 & 7 & 44 & 10 \\
\hline Awake/active & I & 7 & 1 & 5 & 5 & 31 & 7 \\
\hline \multicolumn{8}{|l|}{60 minutes } \\
\hline Asleep/no response & 4 & 36 & 2 & 14 & 0 & 0 & 6 \\
\hline Asleep/responds & 2 & 18 & 4 & 29 & 0 & 0 & 6 \\
\hline Drowsy & 4 & 36 & 4 & 29 & 1 & 8 & 9 \\
\hline Awake/calm & 0 & 0 & 4 & 29 & 6 & so & 10 \\
\hline Awake/active & I & 9 & 0 & 0 & 5 & 42 & 6 \\
\hline
\end{tabular}

demonstrated a slight but statistically significant, $P<$ 0.01 , decrease in systolic blood pressure over time in Groups II (OTFC 15-20 $\mu \mathrm{g} \cdot \mathrm{kg}^{-1}$ ) and III (placebo) and diastolic blood pressure in Group II during the holding area evaluations. Also, diastolic pressure in Group III was higher than in Groups I and II at 30 min. Group I patients had a significantly lower respiratory rate at $30 \mathrm{~min}$ and both OTFC groups had significantly lower respiratory rates 40 min after beginning OTFC consumption than the placebo group (Figure 3). Although all three groups exhibited linear decreasing trends in respiratory rate during the holding area evaluations, the decreases in Groups I and II were greater than in the placebo group. None of the respiratory rate changes in any of the groups was considered clinically significant.
Patients in Group II had a significantly lower mean oxygen saturation than the other two groups $20 \mathrm{~min}$ after beginning OTFC and patients in both OTFC groups had significantly lower mean $\mathrm{SpO}_{2}$ values than the placebo group at 30 and $40 \mathrm{~min}$ (Figure 4 ). Although all groups experienced linear decreasing trends in $\mathrm{SpO}_{2}$ over the first $30 \mathrm{~min}$, the decreases in both OTFC groups (2.5 and 3.3 per cent in Groups I and II, respectively) were slightly greater than in the placebo group (1.0 per cent). One patient in Groups I and III and four in Group II had an oxygen saturation less than 90 per cent (range 84-89 per cent) at some time during the study. These were transient changes and $\mathrm{SpO}_{2}$ increased to 94-95 per cent when the children were asked to take a deep breath. Mean lowest oxygen saturations were $94.2 \pm 2.2,92.4 \pm 2.8$ and 95.1 
TABLE IV Anxiety data in 105 children given oral transmucosal fentanyl citrate (OTFC) or a placebo for premedication

\begin{tabular}{|c|c|c|c|c|c|c|c|}
\hline \multirow[b]{3}{*}{ Time, score } & \multicolumn{7}{|c|}{ Number of patients and per cent of group } \\
\hline & \multicolumn{2}{|c|}{$10-15 \mu g \cdot \mathrm{kg}^{-1}$} & \multicolumn{2}{|c|}{$15-20 \mu g \cdot \mathrm{kg}^{-1}$} & \multicolumn{2}{|c|}{ Placebo } & \multirow{2}{*}{$\frac{\text { Total }}{n}$} \\
\hline & $n$ & per cent & $n$ & per cent & $n$ & per cent & \\
\hline \multicolumn{8}{|l|}{ Baseline } \\
\hline None & 8 & 22 & 9 & 26 & 10 & 29 & 37 \\
\hline Little & 20 & 56 & 16 & 47 & 16 & 46 & 52 \\
\hline Moderate & 8 & 22 & 5 & 15 & 6 & 17 & 19 \\
\hline Excessive & 0 & 0 & 4 & 12 & 3 & 9 & 7 \\
\hline \multicolumn{8}{|l|}{10 minutes } \\
\hline None & 10 & 28 & 11 & 32 & 12 & 34 & 33 \\
\hline Little & 22 & 61 & 15 & 44 & 17 & 49 & 54 \\
\hline Moderate & 4 & 11 & 6 & 18 & 4 & 11 & 14 \\
\hline Excessive & 0 & 0 & 2 & 6 & 2 & 6 & 4 \\
\hline \multicolumn{8}{|l|}{20 minutes } \\
\hline None & 21 & 58 & 18 & 53 & 17 & 49 & 66 \\
\hline Little & 14 & 39 & 11 & 32 & 13 & 37 & 38 \\
\hline Moderate & 1 & 3 & 4 & 12 & 2 & 6 & 7 \\
\hline Excessive & 0 & 0 & 1 & 3 & 3 & 9 & 4 \\
\hline \multicolumn{8}{|l|}{30 minutes } \\
\hline None & 27 & 75 & 24 & 71 & 18 & 51 & 69 \\
\hline Little & 8 & 22 & 5 & 15 & 12 & 34 & 25 \\
\hline Moderate & 1 & 3 & 5 & 15 & 4 & 11 & 10 \\
\hline Excessive & 0 & 0 & 0 & 0 & 1 & 3 & 1 \\
\hline \multicolumn{8}{|l|}{40 minutes } \\
\hline None & 25 & 93 & 19 & 76 & 11 & 46 & 55 \\
\hline Little & 2 & 7 & 3 & 12 & 11 & 46 & 16 \\
\hline Moderate & 0 & 0 & 2 & 8 & 1 & 4 & 3 \\
\hline Excessive & 0 & 0 & 1 & 4 & 1 & 4 & 2 \\
\hline \multicolumn{8}{|l|}{50 minutes } \\
\hline None & 13 & 87 & 19 & 86 & 6 & 38 & 38 \\
\hline Little & 2 & 13 & 2 & 9 & 9 & 56 & 13 \\
\hline Moderate & 0 & 0 & 1 & 5 & 1 & 6 & 2 \\
\hline \multicolumn{8}{|l|}{60 minutes } \\
\hline None & 9 & 82 & 12 & 86 & 6 & 50 & 27 \\
\hline Little & 2 & 18 & 1 & 7 & 6 & 50 & 9 \\
\hline Moderate & 0 & 0 & 1 & 7 & 0 & 0 & 1 \\
\hline
\end{tabular}

\pm 2.3 in Groups I to III, respectively, and the time for the lowest saturation was a median of $\mathbf{3 0}$ min for Groups I and II and $10 \mathrm{~min}$ for group III.

Blood pressure and heart rates of the three groups were comparable prior to anaesthetic induction and demonstrated similar trends throughout the induction-intubation sequence and the remainder of the operative procedure.

The three groups were comparable in the times to extubation at the end of the operations as well as the times to awakening, first response to verbal command and the times to discharge from the recovery room (Table III). Eighteen of the 35 patients having a placebo (51 per cent) required a pain medication in the recovery room whereas 8 of 36 ( 22 per cent) and 15 of 34 ( 44 per cent) of Groups I and II patients, respectively, required an analgesic, (Table V). The difference in analgesic requirements between Groups I and III was statistically significant $(P<$ 0.005 ) but the differences between Groups I and II and II and III were not.

There was no difference in the number of children who were crying, occasionally crying or thrashing in the three groups in the recovery room, irrespective of whether they did or did not receive postoperative pain medication. However, patients in the placebo group were significantly $(P<0.005)$ quieter (more cooperative) than patients in the two OTFC groups. This was due to the fact that a higher percentage of the placebo group received postoperative opioids. When only patients who did not receive opioid analgesics were compared there was no difference in the incidence of quiet (cooperative) patients in the three groups.

In the outpatient discharge unit the three groups were 


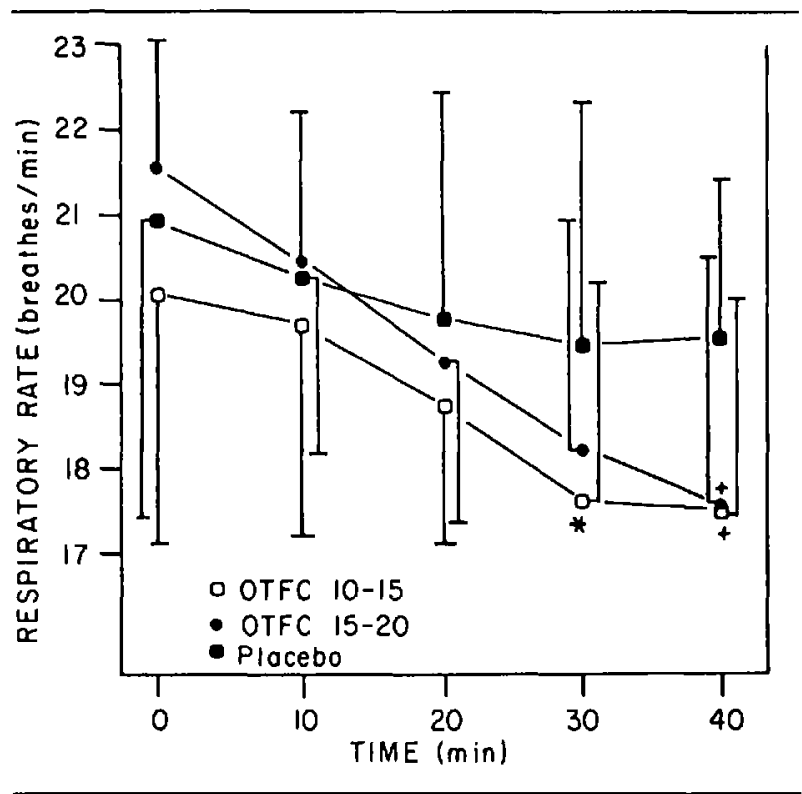

FIGURE 3 Respiratory rate as a function of time (mean \pm SD). Except at $40 \mathrm{~min}$ there were 36 patients receiving OTFC, 10-15 $\mu \mathrm{g} \cdot \mathrm{kg}^{-1}, 34$ receiving OTFC, $15-20 \mu \mathrm{g} \cdot \mathrm{kg}^{-1}$, and 35 receiving a placebo for premedication. $* P<0.05, \dagger P<0.025$ when compared with placebo, Tukey multiple pairwise comparison tests.

statistically comparable in times to stable vital signs, times to ambulation and times to orientation; however, Group III patients could tolerate fluids sooner than either of the two OTFC groups and Group III patients were able to meet all criteria for discharge significantly sooner than Group I (Table VI). There were no statistical differences between Groups I versus II and II versus III in times that all discharge criteria were met.

Pruritus, nausea and vomiting were the three most common side-effects observed during the study. Mild facial pruritus occurred in the preoperative holding area in 58 and 76 per cent of Groups I and II and 23 per cent of Group III (the placebo group) and coincided with the onset of sedation (Table VII). The differences in the incidence of pruritus between the two OTFC groups and

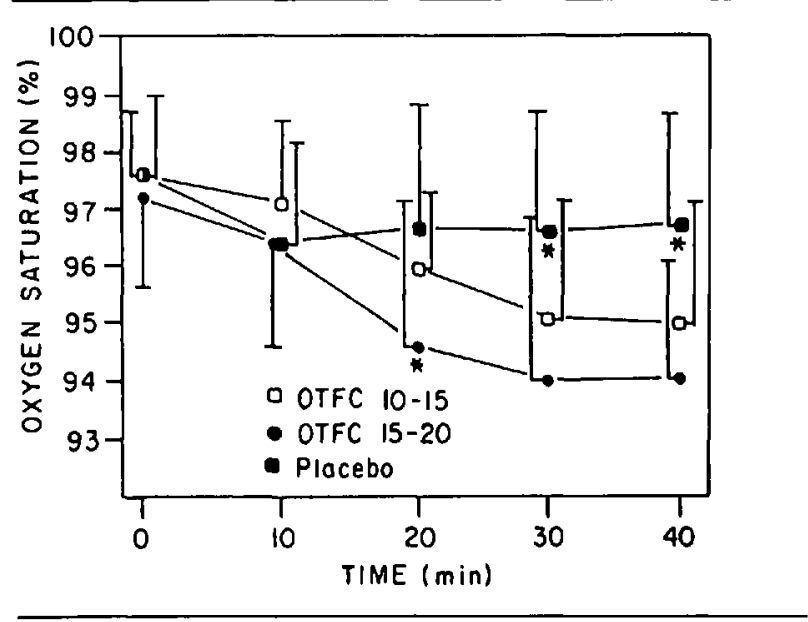

FIGURE 4 Oxygen saturation as a function of time (mean \pm SD). Except at 40 min there were 36 patients receiving OTFC, 10- 15 $\mu \mathrm{g} \cdot \mathrm{kg}^{-1}, 34$ receiving OTFC, $15-20 \mu \mathrm{g} \cdot \mathrm{kg}^{-1}$, and 35 receiving a placebo for premedication. $* P<0.05$, when compared to the other two groups. Tukey multiple pairwise comparisons tests.

the placebo group were statistically significant. Pruritus did not occur in any patient in the operating or recovery rooms or postoperative discharge area. Differences in the incidences of nausea amongst the three groups in the preoperative holding area, operating and recovery rooms and postoperative discharge unil or in all four areas combined were not statistically significant (Table VII).

Differences in the incidences of vomiting amongst the three groups in the four areas of evaluation (the preoperative holding area, the operating and recovery rooms and the post-discharge unit), or in all four areas combined were not statistically significant (Table VII). However, if data from both OTFC groups were combined and compared to the placebo group the incidence of vomiting was significantly higher in the preoperative holding area, although not in the operating and recovery rooms or outpatient discharge area. The first $14(5,4$ and 5 patients in Groups I to III, respectively) of the 105 patients in the

TABLE $V$ Recovery room data in 105 children given oral transmucosal fentanyl citrate (OTFC) or a placebo for premedication (mean $\pm \mathrm{SD}$ )*

\begin{tabular}{llll}
\hline & $\begin{array}{l}\text { Group I } \\
\text { OTFC } \\
10-15 \mu \mathrm{g} \cdot \mathrm{kg}^{-1}\end{array}$ & $\begin{array}{l}\text { Group II } \\
\text { OTFC } \\
15-20 \mu \mathrm{g} \cdot \mathrm{kg}^{-1}\end{array}$ & $\begin{array}{l}\text { Group III } \\
\text { Plocebo }\end{array}$ \\
\hline $\begin{array}{l}\text { Awakening (spontaneous eye opening; } \\
\text { min) }\end{array}$ & $25.3 \pm 16.7$ & $27.3 \pm 20.0$ & $17.2 \pm 9.3$ \\
$\begin{array}{l}\text { First response to verbal command } \\
\text { (min) }\end{array}$ & $30.2 \pm 15.7$ & $33.7 \pm 28.2$ & $22.9 \pm 9.9$ \\
$\begin{array}{l}\text { Recovery room discharge (min) } \\
\text { Patients requiring an analgesic (\%) }\end{array}$ & $\begin{array}{l}47.3 \pm 15.4 \\
22 \% \dagger\end{array}$ & $\begin{array}{l}49.9 \pm 23.6 \\
44 \%\end{array}$ & $\begin{array}{l}43.8 \pm 11.7 \\
51 \%\end{array}$ \\
\hline
\end{tabular}

*Recovery room times were elapsed from the time all inhalational anaesthetics were discontinued. $\dagger P<0.005$, chi-square test when compared to Group III. 
TABLE VI Outpatient postoperative discharge unit data in I05 children given oral transmucosal fentanyl citrate (OTFC) or a placebo for premedication (mean $\pm \mathrm{SD}$ )*

\begin{tabular}{lllr}
\hline & $\begin{array}{l}\text { Group I } \\
\text { OTFC } \\
10-15 \mu g \cdot \mathrm{kg}^{-1}\end{array}$ & $\begin{array}{l}\text { Group II } \\
\text { OTFC } \\
15-20 \mu \mathrm{g} \cdot \mathrm{kg}^{-1}\end{array}$ & $\begin{array}{l}\text { Group III } \\
\text { Placebo }\end{array}$ \\
\hline Time vital signs stable (min) & $108.1 \pm 20.3$ & $108.8 \pm 25.8$ & $102.6 \pm 23.7$ \\
Time patient ambulant (min) & $204.7 \pm 74.3$ & $182.8 \pm 80.4$ & $169.1 \pm 71.9$ \\
Time palient oriented (min) & $101.3 \pm 60.5$ & $114.1 \pm 51.8$ & $89.7 \pm 61.2$ \\
Time patient can tolerate fluids (min) & $227.0 \pm 85.5 \dagger$ & $226.8 \pm 83.7 \dagger$ & $178.9 \pm 90.4$ \\
Time all discharge criteria met (min) & $246.1 \pm 74.1 \dagger$ & $229.5 \pm 78.3$ & $196.9 \pm 77.4$ \\
\hline
\end{tabular}

*Outpatient discharge unit times were elapsed from the time all inhalational anaesthetics were discontinued. $\dagger P<0.05$, Kruskal-Waltis ANOVA and Dunn's multiple comparisons when compared with Group III.

TABLE VII Incidence (percentage) of side effects in children receiving oral transmucosal fentanyl citrate (OTFC) or a placebo

\begin{tabular}{|c|c|c|c|}
\hline & $\begin{array}{l}\text { Group I } \\
\text { OTFC } \\
10-15 \mu \mathrm{g} \cdot \mathrm{kg}^{-1} \\
n=36\end{array}$ & $\begin{array}{l}\text { Group } / / \\
\text { OTFC } \\
15-20 \mu \mathrm{g} \cdot \mathrm{kg}^{-1} \\
11=34\end{array}$ & $\begin{array}{l}\text { Group } / / \\
\text { Placebo } \\
n=35\end{array}$ \\
\hline \multicolumn{4}{|c|}{ Preoperative holding } \\
\hline Pruritus & $58 \% *$ & $76 \% \dagger$ & $23 \%$ \\
\hline Nausea & $14 \%$ & $14 \%$ & 0 \\
\hline Vomiting & $11 \%$ & $14 \%$ & 0 \\
\hline \multicolumn{4}{|c|}{ Operating room } \\
\hline Pruritus & 0 & 0 & 0 \\
\hline Nausea & $3 \%$ & $3 \%$ & 0 \\
\hline Vomiting & 0 & $3 \%$ & 0 \\
\hline \multicolumn{4}{|c|}{ Recovery room } \\
\hline Pruritus & 0 & 0 & 0 \\
\hline Nausea & 0 & 0 & $3 \%$ \\
\hline Vomiting & $14 \%$ & $9 \%$ & $11 \%$ \\
\hline \multicolumn{4}{|c|}{ Posloperative discharge unit } \\
\hline Pruritus & 0 & 0 & 0 \\
\hline Nausea & $8 \%$ & 0 & $3 \%$ \\
\hline Vomiting & $58 \%$ & $47 \%$ & $34 \%$ \\
\hline
\end{tabular}

${ }^{*} P<0.01, \dagger P<0.001$, chi-square test when compared with group III at the same period.

study did not receive droperidol. Overall, 64 per cent of these patients experienced postoperative vomiting, 100 , 25 and 60 per cent in Groups I to III, respectively.

No patient became rigid or required naloxone in the holding area or in the operating or recovery rooms. There was no noticeable decrease in respiratory compliance (as assessed by manual ventilation) in any patient in any of the groups before tracheal intubation; however, abdominal rigidity was noted in one child in Group II shortly after tracheal intubation. One patient (Group I) experienced some airway obstruction and laryngospasm after induction of anaesthesia prior to intubation, one child (Group III) became agitated just before leaving the holding area and another child (Group III) experienced a great deal of airway secretions during induction. Two children in each of Groups I and II complained of dizziness in the holding area and one patient (Group II) had an episode of bigeminy that lasted one minute and abated without treatment during induction of anaesthesia. No other side-effects were noted.

\section{Discussion}

Oral transmucosal fentanyl citrate (OTFC) has not been evaluated previously for use as a premedication in paediatric outpatients undergoing short procedures. Since a large per cent of these patients have their operations in short stay units, it is important to evaluate the usefulness of OTFC in these areas. The results of this study indicate that in children having procedures lasting a mean of 50 min or less in a rapid tumover, short stay unit, OTFC with 
10 to $15 \mu \mathrm{g} \cdot \mathrm{kg}^{-1}$ of fentanyl is an equally effective sedative and anxiolytic premedication as OTFC containing 15 to $20 \mu \mathrm{g} \cdot \mathrm{kg}^{-1}$ of fentanyl. In addition, the lower dose of OTFC produces approximately the same incidence of preoperative and postoperative side-effects as the larger dosage. The data also confirm the findings of the earlier studies that OTFC can reduce postoperative analgesic requirements without appreciably delaying recovery in the recovery room. ${ }^{2-5}$ In this study we found that discharge time from the hospital was somewhat delayed because patients did not tolerate oral fluids as soon as patients who had not received fentanyl. A number of investigators has shown that patients receiving narcotics cannot tolerate fluids as soon and have a higher incidence of early postoperative vomiting than patients not receiving opioids. ${ }^{8,9}$ Bellville et al. ${ }^{10}$ demonstrated that motion increases opioid-induced postoperative nausea and vomiting. This suggests that, if OTFC is used in outpatients having short operations, the patients should be kept immobile and without oral fluids for as long as is practical after surgery. Unfortunately, this will delay discharge from the hospital, as it did in this study, and possibly interfere with the efficiency of the short-stay unit. Alternatively, OTFC should not be given or discharge criteria should be changed to delay oral intake for the first 90 to $120 \mathrm{~min}$. Perhaps this would speed up the ultimate tolerance of oral fluids and not delay discharge.

Patients in this study did not have their stomach emptied routinely (via passage and aspiration of nasogastric or gastric tubes). Smessaert " reduced the incidence of postoperative nausea and vomiting by removing stomach contents with an oral gastric tube. Stanley et al. found that aspiration of stomach contents after the induction-intubation sequence was associated with an incidence of recovery and post-recovery room vomiting of 22 and 6 per cent, respectively, after premedication with OTFC. ${ }^{5}$ While it is difficult to compare incidences of vomiting in different institutions, even in similar patients having similar operations, this data could mean that the aspiration of stomach contents after premedication with OTFC reduces the incidence of postoperative nausea and vomiting.

The available data with patients not receiving droperidol $(n=14)$ is insufficient in this study to make a strong statement regarding the efficacy of droperidol as an anti-emetic after OTFC. Additional work with droperidol, metoclopramide and perhaps other anti-emetics after premedication with OTFC may provide additional useful information.

We believe that the similar efficacy and incidence of side-effects of Groups I and II indicates that 10 to 15 $\mu \mathrm{g} \cdot \mathrm{kg}^{-1}$ is a preferable dosage of OTFC for premedica- tion in outpatients in short stay units. Low $\mathrm{SpO}_{2}$ values were not a problem in this study and have not been a problem in any study in which OTFC doses of 15 to 20 $\mu \mathrm{g} \cdot \mathrm{kg}^{-1}$ or lower were used. ${ }^{2-5}$ Nonetheless, the somewhat higher mean $\mathrm{SpO}_{2}$ values in the preoperative holding area in Group I than Group II patients and the fact that only one patient in Group I versus four in Group II had a $\mathrm{SpO}_{2}<90$ per cent (albeit transient and easily treated by asking the patient to take a breath) suggests to us that the lower dose of OTFC is probably more appropriate.

Chest wall rigidity and reduced ventilatory compliance were not noted in this study and have been rarely if ever seen in other reports of OTFC. ${ }^{1-5}$ We believe absence of these problems is related to the fact that plasma fentanyl concentrations rise slowly after OTFC (compared to IV administration), do not peak until 20 to $30 \mathrm{~min}$ after beginning OTFC administration and only reach 2.5 $\mathrm{ng} \cdot \mathrm{ml}^{-1}$ ?

Mild facial pruritus was the most common side-effect in this study, occurring in 58 and 76 per cent of Groups I and II patients. Pruritus has been reported in adult volunteers and in all studies in which OTCF has been evaluated as a paediatric premedication. ${ }^{1-5}$ Onset of pruritus coincided with onset of sedation, and it is difficult to separate the two in a child rubbing his eyes because he is sleepy, and this is usually not disturbing to the child or his or her parents. While sufficient plasma fentanyl is present to produce postoperative analgesia, pruritus is rarely reported postoperatively and was not noted in any patient in this study.

It has been suggested that non-opioid sedatives, particularly a benzodiazepine such as midazolam, be considered for use as a paediatric premedicant in order to avoid opioid-induced side-effects. ${ }^{12-13}$ Unfortunately, no nonopioid sedative is approved for use as a premedicant in this patient population. In addition, midazolam is bitter and has a slow onset when administered orally and causes children to cry when administered nasally.

While the results of this study suggest that OTFC may be safe and effective as a premedicant for paediatric outpatients having short operations in a rapid turnover environment, it also demonstrates that nausea and vomiting are problems that need to be addressed if OTFC is 10 be useful in this patient population. Also, additional studies in sick (ASA class III and IV) and healthier patients (ASA class I and II) having a variety of other operations need to be accomplished before the advantages and disadvantages of OTFC in outpatients are well established. An effective anti-emetic that would enable children to have a lower incidence of postoperative vomiting and tolerate oral fluids sooner would be of great benefit. 


\section{References}

1 Stanley TH, Hague B, Mock DL et al. Oral transmucosal fentanyl citrate (lollipop) premedication in human volunteers. Anesth Analg 1989; 69: 21-7.

2 Streisand JB, Stanley TH, Hague B et al. Oral transmucosal fentanyl citrate premedication in children. Anesth Analg 1989; 69: 28-34.

3 Nelson PS, Streisand JB, Mulder SM et al. Comparison of oral transmucosal fentanyl citrate and an oral solution of meperidine, diazepam and atropine for premedication in children. Anesthesiology 1989; 70: 616-21.

4 Feld LH, Champeau MW, van Steennis CA et al. Preanesthetic medication in children: a comparison of oral transmucosal fentanyl citrate versus placebo. Anesthesiology 1989; 71: 374-7.

5 Stanley TH, Leiman BC, Rawal Net al. The effects of oral transmucosal fentanyl citrate premedication on preoperative behavioral responses and gastric volume and acidity in children. Anesth Analg 1989; 69: 328-35.

6 Aldrete JA, Kroulik A. A post anesthetic recovery score. Anesth Analg 1970; 49: 924-34.

7 Streisand JB, Ashburn MA, Le Maire Let al. Bioavailability and absorption of oral transmucosal fentanyl citrate. Anesthesiology 1989; 71: A230.

8 Dundee JW, Kirwan MJ, Clarke RSJ. Anaesthesia and premedications as factors in postoperative vomiting. Acta Anaesthesiol Scand 1965; 9: 223-31.

9 Risings, Dodgson MS, Steen PA. Isoflurane versus fentanyl for outpatient laparoscopy. Acta Anaesthesiol Scand 1985; 29: 25I-5.

10 Bellville JW. Postanesthetic nausea and vomiting. Anesthesiology 1961; 22: 773-80.

II Smessaert A, Schehr CA, Artusio JF Jr. Nausea and vomiting in the immediate postanesthetic period. JAMA 1959; 170: 2072-6.

12 Wilton NCT, Leigh J, Rosen DR et al. Preanesthetic sedation of preschool children using intranasal midazolam. Anesthesiology 1988; 69: 972-5.

13 Feld LH, Urquhart ML. Feaster WW et al. Premedication in children: oral versus intramuscular midazolam.

Anesthesiology 1988; 69: A745. 